\title{
Sensitive and Rapid Detection of Centromeric Alphoid DNA in Human Metaphase Chromosomes by PNA Fluorescence In Situ Hybridization and Its Application to Biological Radiation Dosimetry
}

\author{
Yumiko Suto*, Momoki Hirai, Miho Akiyama, Toshikazu Suzuki and \\ Nobuyuki Sugiura \\ Department of Radiation Dosimetry, Research Center for Radiation Emergency Medicine, \\ National Institute of Radiological Sciences, 4-9-1 Anagawa, Inage-ku, Chiba 263-8555, \\ Japan
}

Received January 16, 2012; accepted April 25, 2012

\begin{abstract}
Summary Centromeres of human chromosomes contain highly repeated sequences of DNA including alphoid DNA. Because of the complicated genomic organization of the centromere, the distribution of alphoid DNA in chromosomes has not been fully investigated. We conducted fluorescence in situ hybridization using a synthetic peptide nucleic acid as a sensitive probe (PNA-FISH) to detect chromosomal sites of alphoid DNA. As a result, the size variation of centromeric alphoid DNA among chromosomes was visualized with hybridization times as short as $1-2 \mathrm{~h}$. In addition to the inter-chromosomal variation, we detected possible inter-individual variation in the size of alphoid DNA sites, which had been difficult to precisely analyze by conventional molecular and cytogenetic methods. We then applied this sensitive and rapid detection method to evaluate the yield of multicentric chromosomes induced in cultured human peripheral blood lymphocytes by high-dose gamma-irradiation. This PNA-FISH allows us to unequivocally determine centromeres in complexly rearranged chromosomes, confirming its usefulness in biological radiation dosimetry.
\end{abstract}

Key words Alphoid DNA, Centromere, PNA-FISH, Multicentric chromosome, Radiation.

Centromeric regions of primate chromosomes are dominated by alphoid (alpha satellite) DNA, a family of tandemly repeated nontranscribed sequences (Maio 1971). In primate species, the fundamental repeat unit of alphoid DNA is based on ca. 171-bp monomers (Rosenberg et al. 1978, Musich et al. 1980, Maio et al. 1981, Willard and Waye 1991, Alves et al. 1994) found in tandem arrays of lengths $c a$. $250 \mathrm{~kb}$ to $>5,000 \mathrm{~kb}$ (Wevrick and Willard 1989, Oakey and Tyler-Smith 1990). This highly polymorphic family of DNA comprises $c a .5 \%$ of the human genome (Willard and Waye 1987). There are 2 major types of alphoid DNA in the human genome, designated monomeric and higher-order alphoid DNA (Warburton and Willard 1996, Alexandrwv et al. 2001, Rudd and Willard 2004). All normal human centromeres contain large arrays of higher-order alphoid DNA (Warburton and Willard 1996, Alexandrov et al. 2001). These arrays were found to be bordered by more heterogeneous monomeric alphoid DNA (Wevrick et al. 1992, Horvath et al. 2000, Schueler et al. 2001, Guy et al. 2003, Rudd and Willard 2004). Alphoid DNA contains the binding site of the centromere protein B (CENP-B), and plays an important role in the assembly of specific centromere structures in mitotic and meiotic chromosomes (Masumoto et al. 1989, Cooke et al. 1990, Pluta et al. 1992, Mura et al. 1992, Ohzeki et al. 2002, Okada et al. 2007).

*Corresponding author, e-mail: y-suto@nirs.go.jp

DOI: $10.1508 /$ cytologia. 77.261 
The biological characterization and evolution of alphoid DNA have been extensively investigated in human chromosomes (Earnshaw and Rothfield 1985, Earnshaw et al. 1989, Tyler-Smith et al. 1993, Yoda et al. 1993, Rudd et al. 2003, Masumoto et al. 2004, Rudd and Willard 2004, Rudd et al. 2006). However, because of difficulties in analyzing the highly complicated genomic constitution of centromeric regions, the distribution of alphoid DNA sequences in human chromosomes has not been established. In the present study, we precisely detected alphoid DNA sequences in human chromosomes by a sensitive fluorescence in situ hybridization (FISH) method using a peptide nucleic acid (PNA) probe, instead of the usual DNA probes (Matera and Ward 1992).

PNA is a nucleic acid mimic that contains a pseudo-peptide backbone composed of charge neutral and achiral $N$-(2-aminoethyl) glycine units to which the nucleobases are attached via a methylene carbonyl linker (Nielsen et al. 1991, Egholm et al. 1992, 1993). PNA hybridizes with high affinity to complementary DNA sequences, forming PNA-DNA complexes (Leijon et al. 1994, Nielsen and Christensen 1996). In addition to the high thermal stability of complexes, PNADNA binding is highly sensitive to mismatches (Chen et al. 1999). These traits enable PNA probes to be more efficient and useful in applying FISH technology. Early studies (Lansdorp et al. 1996, Martens et al. 1998) suggested the potential for applying PNA probes in quantitative FISH. We conducted PNA-FISH to demonstrate the distribution and size variation of alphoid DNA in human chromosomes. Since PNA probes permit highly specific centromere enumeration with hybridization times as short as 1-2h (Boei et al. 2000), we assessed the potential of this method for the detection of centromeres in radiation-induced multicentric chromosomes, which are difficult to determine by the conventional Giemsa-staining technique especially when complicated chromosome rearrangements are induced by high-dose irradiation (Fomina et al. 2000, Shi et al. 2012).

\section{Materials and methods}

Peripheral blood was collected from 10 healthy donors ( 3 females and 7 males) after obtaining their informed consent. From each blood sample, lymphocytes were isolated and divided into two parts. One part was cultured for $48 \mathrm{~h}$ to make ordinary chromosome preparations. The other part was cultured for $72 \mathrm{~h}$, with a treatment of 5-bromo-2'-deoxyuridine (BrdU, 25 $\mu \mathrm{g} / \mathrm{ml}$ ) for the final $6.5 \mathrm{~h}$, to obtain R-banded chromosome preparations. A blood sample from a donor was used for radiation exposure experiments. A 3-ml blood sample was exposed in vitro to 20-Gy gamma rays at a dose rate of $0.5 \mathrm{~Gy} / \mathrm{min}$ and cultured for $54 \mathrm{~h}$.

PNA-FISH was conducted as described previously (Suto et al. 2011), with modifications. In brief, chromosome preparations were dried in an oven for $2-3 \mathrm{~h}$ at $64^{\circ} \mathrm{C}$, denatured in an alkali-denaturation solution composed of $0.1 \mathrm{~N} \mathrm{NaOH}(70 \%)$ and ethanol $(30 \%)$ at room temperature for $1 \mathrm{~min}$ followed by dehydration in ethanol series. For detection of the centromeric alphoid DNA, a synthesized Cy3-conjugated centromere PNA probe (Panagene, Daejon, South Korea) was used. A total of $60 \mu \mathrm{L}$ probe mix ( $60 \%$ formamide in $2 \times \mathrm{SSC}, 10 \mathrm{ng}$ salmon sperm DNA, $5 \mathrm{ng}$ PNA probe) was denatured at $90^{\circ} \mathrm{C}$ for $5 \mathrm{~min}$, dropped onto a slide to hybridize to alkali-denatured chromosomes, covered with a piece of plastic film and kept at room temperature for $1-2 \mathrm{~h}$ in the dark. Then, the slide was washed in a post-hybridization solution $(2 \times \mathrm{SSC} / 0.1 \%$ Tween-20) for $10 \mathrm{~min}$ at $57^{\circ} \mathrm{C}$, air-dried, and counterstained with $125 \mathrm{ng} / \mathrm{ml} \mathrm{4,6-diamidine-2-phenylindole} \mathrm{(DAPI).}$

Chromosomes and hybridization signals were observed under a fluorescence microscope (Olympus BX-51, Tokyo, Japan) equipped with a charge-coupled device (CCD) camera (Persuit, Diagnostic Instruments, Inc., MI, USA) connected to a filter-wheel set (Ludl Electronic Products, NY, USA). For the analysis of fluorescent signals on chromosomes, metaphase images obtained from filter sets specific for DAPI and Cy3 were merged using image-processing software (Diagnostic Instruments, Inc., MI, USA). The number of multicentric chromosomes was determined as the dicentric equivalent count (the number of centromeres minus one equals the dicentric 
equivalent count) by viewing under the microscope and confirmed by either the analysis of printed images or monitor-based metaphase analysis. Only metaphase spreads with 46 centromeres were analyzed.

\section{Results and discussion}

Distribution of the hybridization signals of PNA probe for the consensus alphoid sequence in human chromosomes

Centromeric regions in the human genome are abundant with a variety of repeated sequences and segmental duplications. The regions still remain as sequence gaps in the public human genome database (Human Genome Assembly hg19, Feb. 2009). Therefore, precise quantitative information on size differences in different chromosomes is insufficient to date (Rudd and Willard 2004).

Figure 1 shows the results of PNA-FISH with the Cy3-conjugated centromere probe on R-banded human chromosomes. Alphoid DNA sites were present in the centromeric regions of all chromosomes, although the size of the hybridization signals, reflecting the signal intensity, varied significantly between chromosomes. Alphoid DNA sequences on chromosome 2 at band q21 that have been regarded as one of ancient centromeric sequences in human chromosomes (Baldini et al. 1993) could not be visualized without strongly intensifying the CCD camera captured signals using image processing software. Alphoid DNA flanking an L1 could be transduced to a new location during the L1 retrotransposition event, and would produce small stretches of alphoid DNA sites outside of their normal centromeric locations. However, the synthesized 18-mer PNA probe, designed on the basis of the consensus sequence of alphoid DNA (Choo et al. 1991), did not show any such hybridization signals outside the centromeric regions of chromosomes under the present experimental conditions. The relative fluorescence intensities of centromeric signals were as follows: chromosomes 9, 14, 18, 20, and 22 exhibited strong signals; chromosomes 1, 3, 8, 12 and 16 showed weak signals; other chromosomes (chromosomes 2, 4, 5, 6, 7, 10, 11, 13, 15, 17, 19, 21 and $\mathrm{X}$ ) exhibited signals with intermediate intensity. In Fig. 2, the intensity of signals is displayed as a rainbow-color gradient from weak to strong intensity generated by image processing software (PhotoStudio, ArcSoft, CA, USA).

The following chromosomes showed characteristic hybridization signal patterns. In a certain proportion of metaphase plates, chromosome 4 showed 2 signals; a major signal at the primary constriction and an additional signal located slightly distal to the major one on either the short or long
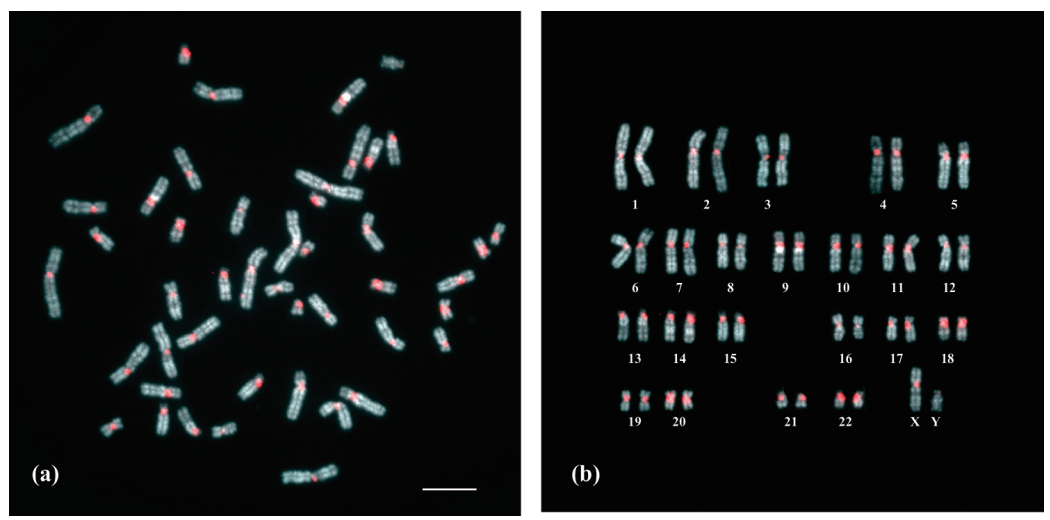

Fig. 1 Fluorescence in situ hybridization of a peptide nucleic acid (PNA) probe to human chromosomes. (a) Hybridization signals of a Cy3-conjugated centromere probe (red) on R-banded metaphase chromosomes (gray-scale) from a male donor. (b) R-banded karyotype reconstructed from (a). Scale bar $=10 \mu \mathrm{m}$. 


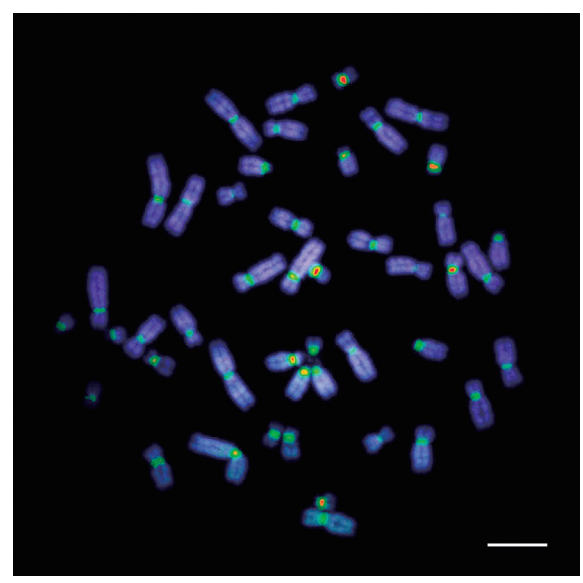

Fig. 2 Computer-generated signal images on a female methaphase plate. Signal intensity is displayed with a rainbow-color gradient from weak (blue) to strong (red). Centromeres of chromosomes 18, 20 and 22 exhibited strong signals. Scale bar= $10 \mu \mathrm{m}$.

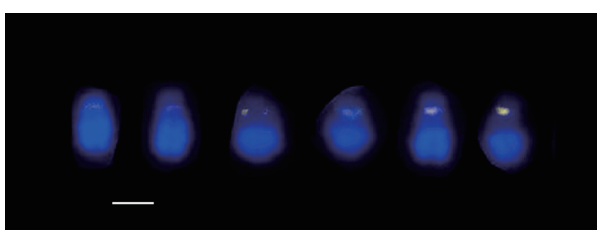

Fig. 3 Size variation in the hybridization signals of $\mathrm{Y}$ chromosomes from 6 males. For comparison, standardized signal intensities of chromosomes 1 and 2 were used as internal controls. Scale bar $=1 \mu \mathrm{m}$. arm. However, this signal pattern was not consistently observed in every metaphase plate. The same holds for other chromosomes, such as chromosomes 9, 14, 18 and 22, with relatively large signals. It is unclear at present whether these inter-cellular variations are due to the presence of cells having spontaneously inverted chromosomes.

Our findings suggest inter-individual variation in the size of the hybridization signals in chromosomes, although the degree of variation seems insignificant as compared to inter-chromosomal variation. Only the Y chromosome showed exceptionally recognizable inter-individual variation (Fig. 3). This is in agreement with an early study (Abruzzo et al. 1996) in which size variation in the alphoid DNA of the $\mathrm{Y}$ chromosome was detected by long-range restriction enzyme analyses. Further quantitative investigations by PNA-FISH may uncover individual variation in the content of the alphoid DNA and its biological significance.

\section{Application of PNA-FISH to the detection of centromeres in radiation-induced multicentric chromosomes}

As shown in Fig. 4, centromeric regions were hybridized with the Cy3-labeled probe, resulting in the unequivocal localization of centromeres in multicentric chromosomes. In a computer-processed negative image, dark signals stand out against yellowish chromosomes.

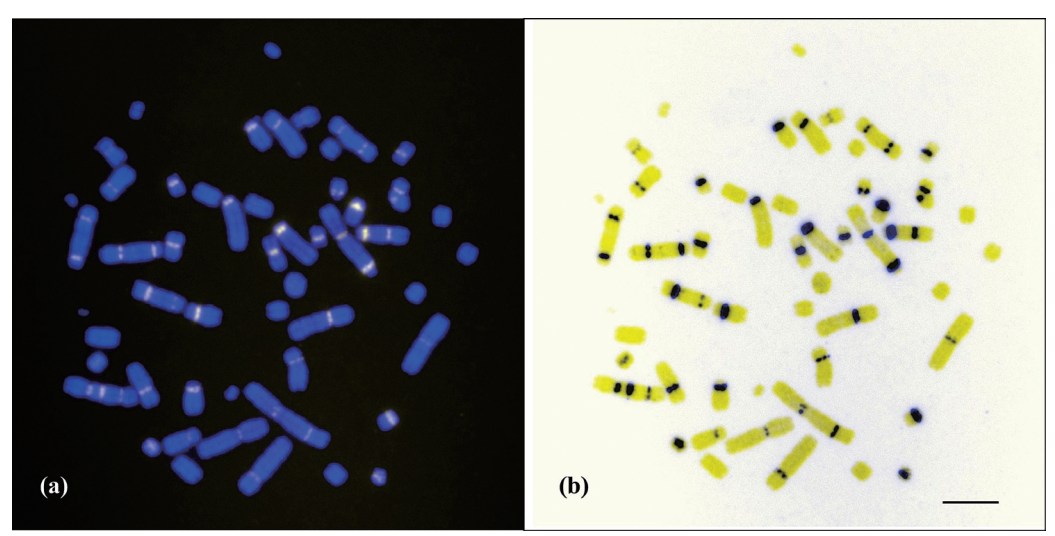

Fig. 4 A metaphase plate obtained from cultured peripheral blood lymphocytes after 20-Gy gamma-ray irradiation. (a) Hybridization signals are highlighted in white on DAPI-stained chromosomes (blue). (b) The negative image of the same metaphese plate as (a) generated by image processing software. Scale bar $=10 \mu \mathrm{m}$. 
Centromeric regions have been conventionally detected by C-banding and FISH with DNA probes (Meyne et al. 1989). These procedures, however, are labor and time consuming. It is evident that the PNA-FISH method has advantages over the conventional methods (Shi et al. 2012).

Unexpectedly, the above-mentioned advantages with respect to the highly sensitive PNA probe caused a type of limitation. A chromosome breakage occurring in a centromeric region results in two signals. This may cause an overestimation of the number of centromeres in a metaphase chromosome plate. There were also cells with chromosomes having tiny dot-like signals in addition to 46 centromeric signals (Fig. 5). We denoted this type of signal as an interstitial minor signal. Chromosome breakage occurring in the vicinity of alphoid sequences outside the functional centromere unit may produce additional minor signals. In fact, 12 metaphase plates showed one to four additional minor signals in a total of 130 metaphase plates examined. When a metaphase plate contained more than 46 centromeric signals, careful examinations on the chromosomal constitution were conducted to exclude these additional signals from multicentric chromosome scoring. Careful examinations were also conducted on extraordinary large signals. Karyotype analyses revealed that most of such large signals were originated from two centromeric signals located close to each other.

Taking into consideration these features of hybridization signals, we evaluated the dicentric equivalent counts in a total of 100 metaphase plates (Table 1). The average dicentric equivalent count was 12.8. The distribution of dicentric equivalent counts per cell was studied for variance analysis by variance/mean ratio (V/m; coefficient of variance) and goodness-of-fit to the Poisson distribution by chi-square statistics. The distribution was under-dispersed $(\mathrm{V} / \mathrm{m}<1)$, and deviation from the Poisson distribution was statistically significant.

To our knowledge, this is the first report on the evaluation and characterization of the yield of multicentric chromosomes induced by high levels of irradiation, as high as $20 \mathrm{~Gy}$, using PNAFISH. Interestingly, the distribution of dicentric equivalent counts per cell in the high-dose range

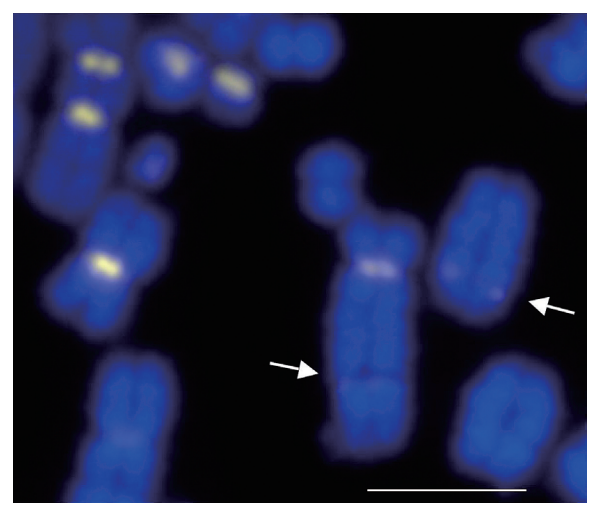

Fig. 5 Partial metaphase plate showing interstitial minor signals (arrows). Scale bar $=5 \mu \mathrm{m}$. was different from that in the low-dose range, in which the distribution follows the Poisson distribution (IAEA 2001). Factors that influence the deviation from the Poisson distribution may include cell killing, double-strand DNA break induction and cell cycle kinetics, which may be specific for high-dose irradiation.

In conclusion, we conducted FISH to rapidly visualize centromeric sites on human chromosomes using the PNA probe for the consensus sequence of alphoid DNA. The PNA probe permits highly specific centromere detection with hybridization times as short as $1-2 \mathrm{~h}$. Our findings indicate that the use of PNA-FISH can shed further light on the induction of multicentric chromosomes by high-dose irradiation.

Table 1. Frequency and distribution of dicentric equivalent counts per cell in cultured human peripheral blood lymphocytes irradiated in vitro with $20-$ Gy gamma rays

\begin{tabular}{|c|c|c|c|c|c|c|c|c|c|c|c|c|c|c|c|c|c|}
\hline \multirow{2}{*}{$\begin{array}{l}\text { Number } \\
\text { of cells } \\
\text { analyzed }\end{array}$} & \multicolumn{13}{|c|}{ Dicentric equivalents/cell } & \multirow{2}{*}{$\begin{array}{c}\text { Total } \\
\text { dicentric } \\
\text { equivalents }\end{array}$} & \multirow{2}{*}{ Mean \pm SE } & \multirow{2}{*}{$\mathrm{V} / \mathrm{m}$} & \multirow{2}{*}{$\begin{array}{c}\text { Goodness-of- } \\
\text { fit to Poisson } \\
\text { distribution } \\
\text { probability }\end{array}$} \\
\hline & 7 & 8 & 9 & 10 & $11 \quad 12$ & 13 & 14 & 15 & 16 & 17 & 18 & 19 & 20 & & & & \\
\hline 100 & 2 & 3 & 3 & 10 & $11 \quad 15$ & 19 & 11 & 15 & 4 & 4 & 2 & 0 & 1 & 1280 & $12.80 \pm 0.36$ & 0.476 & $0.05>p$ \\
\hline
\end{tabular}




\section{Acknowledgment}

The authors would like to thank Mr. Mamoru Kato, CBC Co., Ltd., Tokyo, Japan, for helpful technical information.

\section{References}

Abruzzo, M. A., Griffin, D. K., Millie, E. A., Sheean, L. A. and Hassold, T. J. 1996. The effect of Y-chromosome alphoid array length on the rate of sex chromosome disomy in human sperm. Hum. Genet. 97: 819-823.

Alexandrov, I., Kazakov, A., Tumeneva, I., Shepelev, V. and Yurov, Y. 2001. Alpha satellite DNA of primates: Old and new families. Chromosoma 110: 253-266.

Alves, G., Seuanez, H. N. and Fanning, T. 1994. Alpha satellite DNA in neotropical primates (Platyrrhini). Chromosoma 103: $262-267$.

Baldini, A., Ried, T., Shridhar, V., Ogura, K., D’Aiuto, L., Rocchi, M. and Ward, D. C. 1993. An alphoid DNA sequence conserved in all human and great ape chromosomes: Evidence for ancient centromeric sequences at human chromosomal regions 2q21 and 9q13. Hum. Genet. 90: 577-583.

Boei, J. J. W., Vermeulen, S. and Natarajan, A. T. 2000. Analysis of radiation-induced chromosomal aberrations using telomeric and centromeric PNA probes. Int. J. Radiat. Biol. 76: 163-167.

Chen, C., Hong, Y. K., Ontiveros, S. D. E., Egholm, M. and Strauss, W. M. 1999. Single base discrimination of CENP-B repeats on mouse and human chromosomes with PNA-FISH. Mamm. Genome 10: 13-18.

Choo, K. H., Vissel, B., Nagy, A., Earle, E. and Kalitsis, P. 1991. A survey of the genomic distribution of alpha satellite DNA on all the human chromosomes, and derivation of a new consensus sequence. Nucleic Acids Res. 19: 11791182 .

Cooke, C. A., Bernat, R. L. and Earnshaw, W. C. 1990. CENP-B: a major human centromere protein located beneath the kinetochore. J. Cell Biol. 110: 1475-1488.

Earnshaw, W. C. and Rothfield, N. 1985. Idendification of a family of human centromere proteins using autoimmune sera from patients with scleroderma. Chromosoma 91: 313-321.

—, Rtrie, III., H. and Stetten, G. 1989. Visualization of centrosome protein CENP-B and CENP-C on a stable dicentric chromosome in cytological spreads. Chromosoma 98: 1-12.

Egholm, M. Buchardt, O., Nielsen, P. E. and Berg, R. H. 1992. Peptide nucleic acids (PNA): oligonucleotide analogues with an achiral peptide backbone. J. Am. Chem. Soc. 114: 1895-1897.

—, -, Christensen, L. Behrens, C., Freier, S. M., Driver, D. A., Berg, R. H., Kim, S. K., Norden, B. and Nielsen, P. E. 1993. PNA hybridizes to complementary oligonucleotides obeying the Watson-Crick hydrogen-bonding rules. Nature 365: 566-568.

Fomina, J, Darroudi, F., Boei, J. J. and Natarajan, A. T. 2000. Discrimination between complete and incomplete chromosome exchanges in X-irradiated human lymphocytes using FISH with pan-centromeric and chromosome specific DNA probes in combination with telomeric PNA probe. Int. J. Radiat. Biol. 76: 807-813.

Guy, J., Hearn, T., Crosier, M., Mudge, J., Viggiano, L., Koczan, K., Thiesen, H. J., Bailey, J. A., Horvath, Eichler, E. E., Earthrowl, M. E., Deloukas, P., French, L., Rogers, J., Bentley, D. and Jackson, M. S. 2003. Genomic sequence and transcriptional profile of the boundary between pericentromeric satellites and genes on human chromosome arm 10p. Genome Res. 13: 159-172.

Horvath, J. E., Viggiano, L., Loftus, B. J., Adams, M. D., Archidiacono, N., Rocchi, M. and Eichler, E. E. 2000. Molecular structure and evolution of an $\alpha$ satellite/non- $\alpha$ satellite junction at 16p11. Hum. Mol. Genet. 9: 113-123.

IAEA (International Atomic Energy Agency). 2001. Cytogenetic analysis for radiation dose assessment. A manual. Technical Report Series No. 405. IAEA., Vienna.

Lansdorp, P. M., Verwoerd, N. P., van de Rijke, F. M., Dragowska, V., Little, M-T. Dirks, R. W., Raap, A. K. and Tanke, H. J. 1996. Heterogeneity in telomere length of human chromosomes. Hum. Mol. Genet. 5: 685-691.

Leijon, M., Graslund, A., Nielsen, P. E., Buchardt O., Norden, B., Kristensen, S. M. and Erikson, M. 1994. Structural characterization of PNA-DNA duplexes by NMR. Evidence for DNA in a B-like conformation. Biochemistry 33: 9820-9825.

Maio, J. J. 1971. DNA strand reassociation and polynucleotide binding in the African green monkey, Cercopithecus aethiops. J. Mol. Biol. 56: 579-595.

Maio, J. J., Brown, F. L. and Musich, P. R. 1981. Toward a molecular paleontology of primate genomes. Chromosoma 83: $103-125$.

Martens, U. M., Mark, J., Zijlmans, J. M., Poon, S. S. S., Dragowska W. Yui, J., Chavez, E. A., R. Ward, R. K., and Lansdrop, P. M. 1998. Short telomeres on human chromosome 17p. Nature Genet. 18: 76-80.

Masumoto, H., Masukata, H., Muro, Y., Nozaki, N. and Okazaki, T. 1989. A human centromere antigen (CENP-B) inter- 
acts with a short specific sequence in alphoid DNA, a human centromeric satellite. J. Cell Biol. 109: 1963-1973.

-, Nakano, M. and Ohzeki, J. 2004. The role of CENP-B and $\alpha$-satellite DNA: de novo assembly and epigenetic maintenance of human centromeres. Chromosome Res. 12: 543-556.

Matera, A. G. and Ward, D. C. 1992. Oligonucleotide probes for the analysis of specific repetitive DNA sequences by fluorescence in situ hybridization. Hum. Mol. Genet. 1: 535-539.

Meyne, J., Littlefield, L. G. and Moyzis, R. K. 1989. Labeling of human centromeres using an alphoid DNA consensus sequence: application to the scoring of chromosome aberrations. Mutat. Res. 226: 75-79.

Musich, P. R., Brown, F. L. and Maio, J. J. 1980. Highly repetitive component alpha and related alphoid DNAs in man and monkeys. Chromosoma 80: 331-348.

Nielsen, P. E., Egholm, M., Berg, R. H. and Buchardt, O. 1991. Sequence-selective recognition of DNA by strand displacement with a thymine-substituted polyamide. Science 254: 1497-1500.

— and Christensen, L. E. 1996. Strand displacement binding of duplex-forming homopurine PNA to a homopyrimidine duplex DNA target. J. Am. Chem. Soc. 118: 2287-2288.

Oakey, R. and Tyler-Smith, C. 1990. Y chromosome DNA haplotyping suggests that most European and Asian men are descended from one of two males. Genomics 7: 325-330.

Ohzeki, J., Nakano, M., Okada, T. and Masumoto, H. 2002. CENP-B box is required for de novo centromere chromatin assembly on human alphoid DNA. J. Cell Biol. 159: 765-775.

Okada, T., Ohzeki, J., Nakano, M., Yoda, K., Brinkley, W, R., Larionov, V. and Masumoto, H. 2007. CENP-B controls centromere formation depending on the chromatin contex. Cell 131: 1287-1300.

Pluta, F. P., Saitoh, N., Goldberg, I. and Earnshaw, W. C. 1992. Identification of a subdomain of CENP-B that is necessary and sufficient for localization to the human centromere. J. Cell Biol. 116: 1081-1093.

Rosenberg, H., Singer, M. and Rosenberg, M. 1978. Highly reiterated sequences of Simians. Science 200: $394-402$.

Rudd, M. K., Schueler, M. G. and Willard, H. F. 2003. Sequence organization and functional annotation of human centromeres. Cold Spring Harbor Symposium on Quantitative Biology (68th). Cold Spring Harbor Laboratory Press, Plainview. pp. 141-149.

— and Willard, H. F. 2004. Analysis of the centromeric regions of the human genome assembly. Trends Genet. 20: 529533.

—, Wray, G. A. and Willard, H. F. 2006. The evolutionary dynamics of $\alpha$-satellite. Genome Res. 16: 88-96.

Schueler, M. G., Higgins, A. W., Rudd, M. K., Gustashaw, K. and Willard, H. F. 2001. Genomic and genetic definition of a functional human centromere. Science 294: 109-115.

Shi, L., Fujioka, K., Sun, J., Kinomura, A., Inaba, T., Ikura, T., Ohtaki, M., Yoshida, M., Kodama, Y., Livingston, G. K., Kamiya, K. and Tashiro, S. 2012. A modified system for analyzing ionizing radiation-induced chromosome abnormalities. Radiat. Res. 177: 533-538.

Suto, Y., Akiyama, M. and Yamada, Y. 2011. Unequivocal detection of radiation-induced multicentric chromosomes by fluorescence in situ hybridization using peptide nucleic acid probes. Cytologia 76: 1-2.

The Human Genome Reference Consortium. The Human Feb. 2009 Assembly (GRCh37/hg19). URL to: http://www.ncbi. nlm.nih.gov/projects/genome/assembly/grc/index.shtml.

Tyler-Smith, C., Oakey, R. J., Larin, Z., Fisher, R. B., Crocker, M., Affara, N. A., Ferguson-Smith, M. A., Muenke, M., Zuffardi, O. and Jobling, M. A. 1993. Localization of DNA sequences required for human centeromere function through an analysis of rearranged Y chromosomes. Nature Genet. 5: 368-375.

Warburton, P. E. and Willard, H. F. 1996. Evolution of Centromeric $\alpha$-satellite DNA: Molecular Organization within and between Human and Primate Chromosojes. In: Jackson, S.T. and Dover, G. (eds.). Human Genome Evolution. BIOS Scientific Publishers, Oxford. pp. 121-145.

Wevrick, R. and Willard, H. F. 1989. Long-range organization of tandem arrays of $\alpha$-satellite DNA at the centromeres of human chromosomes: high frequency array-length polymorphism and meiotic stability. Proc. Natl. Acad. Sci. U.S.A. 86: 9394-9398.

Wevrick, R., Willard, V. P. and Willard, H. F. 1992. Structure of DNA near long tandem arrays of $\alpha$-satellite DNA at the centromere of human chromosome 7. Genomics 14: 912-923.

Willard, H. F. and Waye, J. S. 1987. Hierarchical order in chromosome-specific human alpha satellite DNA. Trends Genet. 3: 192-198.

— 1991. Evolution of alpha satellite. Curr. Opin. Genet. Dev. 1: 509-514.

Yoda, K., Kitagawa, K., Masumoto, H., Muro, Y. and Okazaki, T. 1993. A human centromere protein, CENP-B, has a DNA binding domain containing four potential $\alpha$ helices at the $\mathrm{NH}_{2}$ terminus, which is separable from dimerizing activity. J. Cell Biol. 119: 1413-1427. 